\title{
DISCURSOS INTERNOS SE SUSTENTAM SEMI SUPORTE DA CONTABILIDADE GERENCIAL? UM ESTUDO DE CASO NO SETOR DE AUTOPEÇAS
}

\author{
DO INTERNAL DISCOURSES HIOLD WITHOUT
}

MIANAGEMENT ACCOUNTING SUPPORT? $\mathbb{A}$ CASE STUDY ON THE AUTO PARTS INDUSTRY

\author{
Fábio Frezatti* \\ Marcelo Francini Girão Barroso** \\ David B. Carter***
}

Resirimo

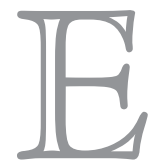

ste trabalho tem como objetivo tratar o relacionamento entre vários discursos organizacionais, estudando o impacto das informações contidas no sistema de informações gerenciais sobre o discurso organizacional. Os discursos organizacionais são criados e trazem impactos na organização. A pesquisa surge motivada pela percepção de que existe uma lacuna relevante que pode ser minimizada ou eliminada ao proporcionar discussão sobre informações provenientes do sistema de informações gerenciais que reforçam, ajustam, legitimam ou destroem discursos. Foi desenvolvido um estudo de caso em uma organização industrial do setor de autopeças, em fase de crescimento, a partir de ferramentas da abordagem action research, em que foram analisados três níveis de discurso organizacional que são as crenças dos sócios, o empreendedorismo e os resultados financeiros reais. A partir da análise, foram estruturadas três proposições. Conclui-se que a ausência de informações gerenciais permite e demanda vários discursos que, embora tentem substituir as informações contábeis, o fazem de forma parcial e, com o passar do tempo, destroem discursos estratégicos.

Palavras-chave: Contabilidade Gerencial. Discursos Organizacionais. Linguagem dos Negócios.

Abstreact

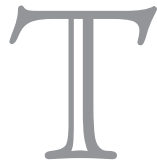

his study examines the relationship among diverse organizational discourses by studying the impact of management information systems on such discourses. Based on the relevant gap in the literature that could be minimized or eliminated, this research raises the discussion about "objective" information

* Doutor em Controladoria e Contabilidade na Universidade de São Paulo, Faculdade de Economia, Administração e Contabilidade (FEA-USP), São Paulo SP, Brasil.

Instituição de vínculo:Professor Titular da Universidade de São Paulo, Faculdade de Economia, Administração e Contabilidade (FEA-USP), São Paulo SP, Brasil.

E-mail: frezatti@usp.br

** Doutor em Ciências (Contabilidade) pela Universidade de São Paulo, Faculdade de Economia, Administração e Contabilidade (FEA-USP), São Paulo SP, Brasil.

Instituição de vínculo: Universidade Presbiteriana Mackenzie (UPM), São Paulo SP, Brasil.

E-mail: marcelo.barroso@mackenzie.br

*** PH.D. pela Victoria University of Wellington, Wellington, Nova Zelândia.

Instituição de vínculo: University of Canberra, Austrália.

E-mail: david.carter@canberra.edu.au 
originating from management information systems, which either strengthens or weakens discourses. A case study was developed regarding a young auto parts industrial organization, and three levels of organizational discourse were analyzed through action research: 1) partners' beliefs; 2) entrepreneurship; and 3) real financial results. The findings indicate that the lack of managerial information raises diverse alternative discourses, which do not substitute for information on financial results. Eventually, the credibility of whoever practices the discourse without the corresponding information on management accounting reports is weakened.

Keywords: Management Accounting. Organisational Discourses. Business Language.

Iñtrodrrção

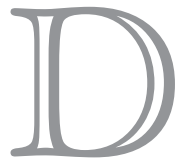

iscurso organizacional é relevante para o direcionamento dos negócios em uma organização. Possibilita aos dirigentes exteriorizar expectativas e orientar os executivos em um dado contexto. Materializa-se em várias situações e pode explicitar o desempenho esperado da organização, transmitido da área financeira para as demais ou mesmo da diretoria para o restante da empresa. Pode ser percebido quando se diz: 'a empresa está melhorando', 'o mercado não se impressiona com resultados financeiros ruins, mas sim com expectativa de resultados favoráveis futuros', ou 'a margem bruta do segmento A é muito boa'. Esses discursos são evidenciados e legitimados por meio de informações contábeis, caracterizando a contabilidade, na prática, como a linguagem dos negócios. A contabilidade contribui para viabilizar o entendimento e o gerenciamento da organização (CHAMBERS, 1974; MACINTOSH, 2002), bem como para a constituição e expressão do discurso organizacional (LAVOIE, 1987).

A linguagem precisa ser interpretada, proporcionando percepção de algum tipo de realidade e, com a contabilidade, não é diferente (KNIGHTS; COLLINSON, 1987; LLEWELLYN; MILNE, 2007). Contudo, a extensão da interpretação da informação da contabilidade gerencial passa por entendimento específico, dado o conjunto de expectativas sobre o que expressa. Ainda, espera-se que informações contábeis não sejam 'mera' interpretação da realidade, mas expressem efetivamente algo 'objetivo' e 'real' (MACINTOSH, 2002; MACINTOSH et al., 2000; MORGAN, 1988). Nesse sentido, as informações gerenciais contábeis contribuem de forma considerável na constituição de discurso organizacional, afetando a gestão da organização.

Conforme Chia (2000, p. 514), compreende-se discurso organizacional por meio do senso ontológico amplo de "trazer à existência um estado 'organizado' ou estabilizado". Ainda,

Por meio da regularização e rotinização das trocas sociais, da formação e institucionalização de códigos de comportamento, regras, procedimentos e práticas etc., o mundo organizacional que passamos a habitar adquire sua externalidade, objetividade e estrutura aparentes (CHIA, 2000, p. 514).

Discurso organizacional é o meio para constituição da organização, ao "circunscrever partes selecionadas do fluxo de experiências fenomenológicas e fixar suas identidades até tornar possível falar sobre elas [organizações] como se fossem entidades sociais naturalmente existentes" (CHIA, 2000, p. 514; BARROSO, 2014). Ainda, a unidade atribuída a uma 'organização' ou a um 'indivíduo' é uma forma de 'fechamento imaginário' (imaginary closure) (LACLAU, 1996; WILLMOTT, 2005) e resulta portanto do exercício de poder em que uma "força social 'particular' assume a representação de uma 'totalidade'"' (LACLAU; MOUFFE, 2001, p. x, grifo do autor). Assim, por exemplo,

[...] pessoas que se reconhecem como 'membros de organizações', e são identificadas como tais por cientistas sociais, engajam-se em práticas articulatórias que representam a diversidade de suas relações como uma totalidade representada pelo termo 'membro organizacional' (ou 'gerente' ou 'trabalhador'). Essas práticas habilitam a reprodução das relações sociais, incluindo suas atividades produtivas (WILLMOTT, 2005, p. 751). 
Se discurso organizacional representa um processo de constituição do objeto social 'organização', a contabilidade representa um dos instrumentos para suporte à força social 'particular' que atua na constituição dessa 'totalidade'. Contabilidade dá poder aos agentes sociais atuantes no âmbito organizacional. Isso ocorre não somente no sentido superficial da interação social, relacionado à disponibilidade da informação e ao subsídio qualificado a processos decisórios - 'poder' de exclusão de outrem do acesso à informação -, mas no sentido de constituição discursiva de uma totalidade a partir da hegemonização de uma prática particular (HOWARTH; STAVRAKAKIS, 2000; LACLAU, 1996). Mais do que isso, ela materializa a tarefa recorrente de interpretação da realidade organizacional complexa, desempenhada pelos 'contadores' (ou, os agentes sociais que se utilizam dessa tecnologia de informações). Pode-se dizer que, mais do que materialização da tarefa de interpretação, contabilidade materializa o potencial de construção dessa realidade (MORGAN, 1988; HINES, 1988). Essa construção se revela também na constituição de discurso organizacional que então constitui a própria organização (BARROSO, 2014).

Como linguagem dos negócios, a contabilidade gerencial tem um papel importante e está baseada em relatórios que consolidam as informações previstas e realizadas durante certo intervalo de tempo. As estratégias planejadas e as ocorrências verificadas são informadas, devem ser entendidas, e ações são decididas e estimuladas (MIRVIS; LAWLER III, 1983). Dessa maneira, discurso organizacional é retroalimentado e, sob a influência da linguagem contábil, os negócios são gerenciados indicando a direção da organização (CHIA, 2000). Relatórios gerenciais com resultados apurados aproximados ao esperado dão base a interpretações alternativas e proporcionam assertividade aos executivos no desenvolvimento de novas estratégias espelhadas em seus planos formais. O inverso é também verdadeiro: resultados muito distantes do planejado destroem as interpretações atuais, reconstituindo discurso organizacional.

O relacionamento entre essas interpretações e o fluxo de oferta de informações da contabilidade gerencial são relevantes no desenvolvimento dos negócios, tanto no que se refere à rotina do dia a dia, como nas questões mais estratégicas. Na ausência de informações ou de informações confiáveis, o que pode ocorrer na organização? Interpretações que tenham relacionamento com as informações contábeis podem desaparecer ou serem mantidas por outras forças que não do fluxo de informações. Essa discussão representa uma lacuna pouco discutida na literatura e que se mostra relevante para o entendimento do impacto da contabilidade sobre os negócios, na ótica do gerenciamento.

No sistema de controle gerencial, deve existir um parâmetro planejado, de alguma forma legitimado na organização. Esse parâmetro 'objetivo' cria, alimenta, reforça e valida as interpretações da realidade organizacional que dão base à constituição discursiva. Costumeiramente é oferecido em reuniões mensais quando o desempenho passado é avaliado e o resultado planejado, futuro, é discutido. Uma interpretação validada gera credibilidade na organização, e a dinâmica dessa perspectiva preserva o modelo de gestão. Essa credibilidade é de vital importância para que os gestores desenvolvam suas atividades e mantenham seus executivos focados nos objetivos organizacionais. A inexistência de sistema de informações gerenciais, ou mesmo a sua existência com baixa credibilidade, demanda apresentações assertivas para substituir a informação formal. Por outro lado, os limites da utilização do conjunto de artefatos também são relevantes para dispor de expectativas realistas (ROSANAS; VELILLA, 2005), onde questionam (i) a 'ilusão do controle', no sentido de discutir a pretensão de controlar 'tudo', e (ii) a ausência de incentivos efetivos para os gestores atingirem suas metas. Nesse ambiente, o desenvolvimento de valores técnicos e morais é crucial para a sobrevivência da organização.

Frezatti, Carter e Barroso (2014) trataram o assunto na perspectiva de que a inexistência de informação contábil gera interesse e demanda por outros tipos de informações para suprir a necessidade de informações pelos gestores. Conforme apresentado, na ausência da contabilidade gerencial como sistema estruturado de informações para suporte a decisões e à gestão da organização, diferentes articulações discursivas emergem, em substituição à - ou melhor, suportadas pela - ausência 
da contabilidade (daí o título accounting without accounting, ou 'contabilizando sem contabilidade'). Naquele caso, a gestão da organização passou a ser embasada sobre as articulações discursivas em relação às 'crenças dos sócios', às lógicas de suporte a 'empreendedorismo', além das próprias 'informações contábeis' (ainda que abandonado como sistema estruturado de informações) (vide na Figura, a seguir).

Esta pesquisa retoma o tratamento do tema pela caracterização do potencial

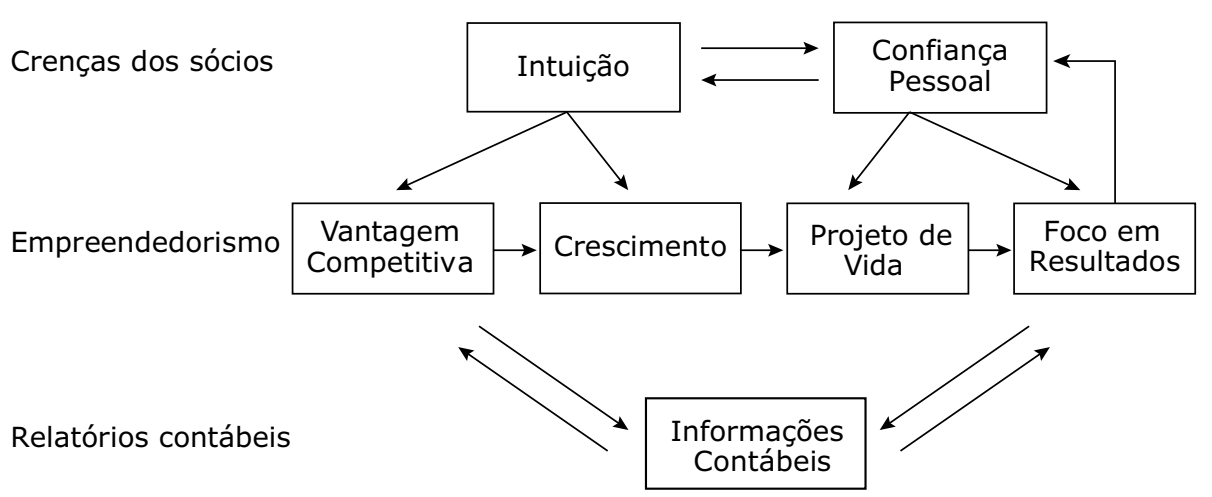

Fonte: Frezatti, Carter e Barroso (2014).

Figura 1 - Relacionamento entre componentes do discurso organizacional

de constituição da organização a partir da tecnologia da contabilidade gerencial. Estudos desenvolvidos na área pressupõem que a informação contábil é desejada e necessária para as atividades gerenciais. Dessa maneira, a contribuição que se pretende proporcionar por esta pesquisa decorre da resposta à questão de pesquisa: Discursos internos se sustentam sem suporte da contabilidade gerencial?

A análise leva em conta a necessidade de entender a realidade percebida na organização, a partir de um paradigma construcionista. Esse posicionamento é definido a priori, e a realidade é entendida como construída e faz parte da vida, do dia a dia, sendo compartilhada entre as pessoas (BERGER; LUCKMANN, 1966). A linguagem é o sistema simbólico que permite o entendimento dessa realidade, não exclusivamente no 'aqui e agora', e proporciona a existência do discurso dos personagens envolvidos nas atividades da organização. Assim, o discurso é um recurso fundamental para que o entendimento da realidade, sendo algo muito mais amplo do que a sequência coerente de sentenças, ditas ou escritas, por meio do qual busca-se o sentido da relação entre sujeitos e objetos (MATTHEWS, 2007).

Este artigo está enraizado na abordagem linguística e na análise retórica. A abordagem linguística se move do passado 'factual', 'objetivo' de apresentação da contabilidade para ver os produtos de contabilidade - números, relatórios, decisões e declarações - como textos, com os contabilistas como os autores do texto, os auditores como os críticos, e os usuários como leitores (MACINTOSH et al., 2000). Este movimento representa uma mudança significativa a partir do foco tradicional de contabilidade como informação, como exigido pela economia. Aqui, a contabilidade é uma narrativa (MACINTOSH, 2002).

Estratuégial metodológical

A perspectiva interpretativista foi adotada como abordagem metodológica, no que se refere à necessidade de entendimento da maneira como os diretores e 
executivos percebem a figura dos relatórios gerenciais. A forma de perceber as informações gerenciais, a sua utilização e a história da empresa são vitais para entender a realidade da entidade pela perspectiva das pessoas que trabalham na organização. Essa abordagem permite entender a realidade como uma experiência subjetiva e de consciência, que coloca o participante em situação oposta ao observador (BURRELL; MORGAN, 1979).

Quanto à técnica de interação com a entidade, que permitiu o entendimento do problema e sua contextualização, foi utilizada a action research (COUGHLAN; COGHLAN, 2002), que permitiu direcionar o foco da pesquisa. A pesquisa foi desenvolvida em uma empresa em que os gestores vivenciavam um processo de transição gerencial e organizacional: investimentos consideráveis haviam sido recentemente realizados, tendo-se mudado a planta industrial de autopeças para outro município e implementadas novas linhas produtivas, complementares às já existentes; no conjunto de mudanças e implementações industriais, inovações gerenciais também ocorriam, considerando a perspectiva de futura abertura de capital. Nesse ínterim, entretanto, problemas no controle gerencial ocorreram, atrelados especialmente a sistemas de informações e à dinâmica própria de tratamento e utilização de informações gerenciais.

Durante um certo tempo, relatórios gerenciais deixaram de ser gerados, deixando-se de subsidiar o corpo gerencial com informações sobre o desenvolvimento das operações e o desempenho dos negócios. Deixou-se, na empresa, de realizar conjunto relevante de práticas de contabilidade gerencial, não obstante à percepção que o espectro da contabilidade continuava presente e influenciando consideravelmente a gestão dos negócios (FREZATTI; CARTER; BARROSO, 2014). Essa situação possibilitou ainda maior riqueza ao desenvolvimento da presente pesquisa.

A abordagem de estudo de caso como contato com o campo e coleta de dados é adequada para o tratamento de problemas complexos em que existe demanda de estudos em profundidade (STAKE, 1995; WEICK, 1995). Houve processo de formalização da autorização da empresa para o desenvolvimento do trabalho, preservando a confidencialidade da entidade e dos personagens.

O trabalho foi conduzido nas instalações da empresa, por dois pesquisadores que utilizaram vários métodos de coleta de dados, sendo: (i) site da empresa para informações sobre história da empresa e suas características gerais; (ii) documental, especificamente o relatório gerencial utilizado até 09/2009; e (iii) entrevistas para esclarecimento de eventos históricos e de negócios, com os sócios (2) e os gerentes, supervisores e analistas (8).

Levando em conta as entrevistas preliminares e o diagnóstico proporcionado pelo procedimento do action research, foram definidas as questões orientadoras utilizadas nas entrevistas com os executivos. Essas questões foram estruturadas de maneira a (i) proporcionar uma visão geral, sob a perspectiva do entrevistado, e (ii) aprofundar o tema, considerando o direcionamento pretendido.

Uma vez proporcionada a visão abrangente, ficou esclarecido que a empresa deixou de usar informações do sistema de contabilidade gerencial, tornando-se esta data de ruptura (Setembro de 2009) um referencial relevante para o entendimento da organização. Posteriormente, foram feitas perguntas mais específicas para aprofundar os temas que interessavam especificamente à pesquisa. Em alguns casos, foi possível gravar a entrevista, mas não em outros, sendo então anotadas as respostas. Foram selecionados como respondentes os diretores (cargos ocupados pelos dois sócios), bem como gerentes, supervisores e assistentes, identificados nos respectivos diálogos conforme Tabela.

Estrudo dle caso $-\mathbb{A}$ emipresal

A empresa analisada é uma organização brasileira, dedicada à produção de componentes metálicos e plásticos a serem utilizados por outras indústrias para montagem de bens duráveis; em suas linhas de atuação, destaca-se a indústria automobilística. Algumas informações sobre a empresa: 
- Fundação e primeiros momentos:

Mais de 50 anos de experiência no mercado brasileiro, nasceu fruto de uma oportunidade proporcionada pela indústria automobilística que demandava fornecedores para amparar o seu crescimento. O fundador foi um ex-funcionário de uma montadora tradicional do país que se associou a um empresário do setor.

Desenvolvimento:

A empresa teve um desenvolvimento de atividades acoplado ao crescimento da indústria automobilística estabelecidas no país, que foi muito grande durante décadas, no início altamente protegida contra as ameaças externas. Posteriormente, após década de 1990, com a abertura do mercado para novas montadoras, o crescimento do número de empresas foi relevante. Por falta de sucessão, o controlador vendeu o controle acionário, em 2007, para dois investidores.

Aquisição por investidores:

Em 2007, dois investidores compraram a empresa. Adotaram uma política agressiva de modernização e crescimento. Aparentemente, a compra estava motivada por uma estratégia de curto prazo, que poderia envolver a venda da empresa para algum investidor estratégico específico, ou mesmo a abertura de capital em bolsa de valores.

\section{Tabela - Respondentes}

\begin{tabular}{|l|c|c|c|}
\hline Descrição & Cargo & Gênero & Presença na entidade \\
\hline S1 & Pesquisador & Masculino & Posterior a 09/2009 \\
\hline S2 & Sócio responsável pela Administração e compras & Masculino & Anterior a 09/2009 \\
\hline S3 & Sócio responsável por marketing, produção e logística & Masculino & Anterior a 09/2009 \\
\hline S4 & Assistente & Feminino & Anterior a 09/2009 \\
\hline S5 & Tesoureiro & Masculino & Anterior a 09/2009 \\
\hline S6 & Comprador & Masculino & Anterior a 09/2009 \\
\hline S7 & Analista de TI & Masculino & Anterior a 09/2009 \\
\hline S8 & Gerente de vendas - área 1 & Masculino & Posterior a 09/2009 \\
\hline S9 & Gerente de vendas - área 2 & Masculino & Posterior a 09/2009 \\
\hline S10 & Coordenadora de RH & Feminino & Posterior a 09/2009 \\
\hline S11 & Coordenadora de contabilidade & Feminino & Posterior a 09/2009 \\
\hline
\end{tabular}

\section{- Mudanças estratégicas:}

A mudança do eixo de crescimento da indústria automobilística mundial para os países emergentes trouxe uma mudança de rumos relevante para a empresa. A expectativa de médio prazo é que um grande número de novas montadoras venha ao Brasil, o que aumenta o potencial de negócios para a empresa. Por outro lado, a pressão dentro da cadeia produtiva torna-se cada vez maior e mais exigente, seja em relação ao acabamento, à segurança, ou ao design. Assim, ao mesmo tempo que a empresa vislumbra oportunidade para converter expectativas de crescimento em realidade, torna-se premente a demanda por maior estruturação, demandando investimentos em pessoas, sistemas e equipamentos, a curto espaço de tempo e em magnitudes para as quais a entidade não estava preparada organizacionalmente, nem financeiramente.

\section{Grande esforço em projetos de inovação}

A empresa, em decorrência das oportunidades geradas pelo mercado, investiu pesadamente em novos processos, trazendo novos produtos e novos clientes. Nesse sentido, sua atuação inicial tinha foco na área metalúrgica, vivendo um intensa mudança com a entrada no segmento de plásticos, tecnologia muito diferente e 
potencial de produtos e mercados também. Esse ambiente de inovação, em que o risco empresarial aumentou substancialmente, foi um elemento de grande motivação para a escolha da empresa. Novos funcionários foram contratados para atender uma estrutura organizacional diferente da anterior. $O$ fato de dispor de estrutura de sistema de informações e tradição em discutir resultados indicou que se trataria de uma empresa ideal para desenvolver o trabalho.

Mudanças relevantes ocorridas nos 12 meses que antecederam a pesquisa: (i) compra de uma empresa de segmento e processo produtivo distintos daqueles que ela estava acostumada a atuar; (ii) mudança de instalações de uma cidade onde a empresa nasceu para outra no interior do Estado e (iii) considerável mudança de pessoas na organização.

Estrudo dle caso - Informaţões obridlas e anålise

Foram coletadas informações das seguintes fontes: (i) site institucional, para informações sobre história da empresa; (ii) documental; e (iii) entrevistas para esclarecimento de eventos históricos e detalhamento de informações sobre os negócios.

As respostas obtidas nas entrevistas foram:

- Pergunta 1. Como vocês gerenciam a empresa e se relacionam com os subordinados?

O objetivo desta pergunta foi entender o estilo de gestão dos diretores, que se revelou personalista, voltado para pessoas; a palavra 'confiança' foi identificada com um sentido especial e agressivo ('discurso das crenças dos sócios'). Na literatura, reconhece-se desde longa data a importância da confiança como elemento crucial no modelo de gestão (ex.: MARCH; SIMON, 1958).

São dois sócios que compartilham espaço de trabalho contíguo e decidem juntos sobre as questões relevantes da organização; ambos se mostram satisfeitos com o modelo de gestão. Essa atuação conjunta permite combinação de talentos e otimização de tempo. Tomam decisões levando em conta as próprias 'intuições' ('discurso das crenças dos sócios'), em vários temas relevantes, principalmente quando se referem a contratações de colaboradores e na avaliação se podem confiar neles. Miller e Friesen (1984) identificaram a característica relevante do processo de gestão da organização nos estágios iniciais do ciclo de vida. Uma vez existindo confiança, o relacionamento se torna possível, e o desempenho consolida essa percepção. Os sócios argumentam que se dedicam exclusivamente à empresa, demonstrando que ela representa a atividade mais relevante de suas vidas. Os diálogos abaixo refletem esses achados:

\section{Sujeito 1: como você pensa em termos de relacionamento com subordinados?}

Sujeito 3: tudo o que eu faço tem foco no resultado. Sempre confio no subordinado. No dia que não confiar, não vai trabalhar comigo. Ou traz resultado ou não traz.

Sujeito 2: Confiança nas pessoas é fundamental e não admitimos deslealdade. Não cometemos um deslize para dar chance de alguém fazer o mesmo. Parei de desenvolver a minha consultoria jurídica para me dedicar $100 \%$. Se o cara não tomou as ações necessárias, ele vai tomar uma paulada.

A contratação e manutenção de executivos que identificam o próprio 'projeto de vida' com a empresa ('discurso do empreendedorismo') é uma abordagem de longo prazo relevante para o modelo. A literatura reconhece isso (ex. ROSANAS; VELILLA, 2005).

Neste estudo, 'projeto de vida' tem a característica de significante vazio (HOWARTH; STAVRAKAKIS, 2000), podendo assumir diversos significados às pessoas. Pode ser a evolução profissional, a imagem de vencedor, a resposta para outra empresa que não deu oportunidade, por exemplo. O importante é que a recompensa seja futura, de longo prazo, enquanto que o esforço, o compromisso e o desafio são demandados imediatamente. Recompensa intangível pode ser a imagem de vencedor, a resposta para outra empresa que não deu oportunidade, etc. É o que a organização está fazendo. Como evidência, pode-se mencionar: 
Sujeito 3: trouxemos um ótimo gerente comercial que só veio para cá por causa do projeto de vida. Ele acreditou no nosso projeto. Deixou de ganhar mais e veio para cá.

Quando falam em prioridades e resultados, os sócios não se referem a resultados financeiros, mas àquilo que percebem das conversas, principalmente elementos operacionais, do dia a dia, tornando-os reféns da rotina e diminuindo a oportunidade de maior enfoque na atividade estratégica da organização. Quando se referem a 'resultados' ('discurso de empreendedorismo'), os sócios sempre são vagos, apresentando também características de significantes vazios (HOWARTH; STAVRAKAKIS, 2000), relevante, portanto, para a combinação de elementos. Afinal a informação contábil serve para a compreensão da situação da organização, tomar decisões e estabelecer metas (HENDRIKSEN; BREDA, 1999). A apuração de resultado é relevante como feedback para os executivos e deveria reforçar o relacionamento com a empresa, sendo fundamental para o executivo saber se ocorreu o que se esperava dele: "In the end, people identify strongly with the goals of the organization and feel energized when they achieve those goals." (ROSANAS; VELILLA, 2005, p. 90).

Percebe-se que a discussão de temas estratégicos é considerada atraente pelos sócios, mas o tempo dispensado para tais atividades é escasso, sendo que a rotina passa a tomar importância acentuada.

Sujeito 1: quais suas prioridades hoje?

Sujeito 3: a prioridade hoje é o resultado da cia.

O mecanismo que alimenta a relação de confiança entre sócios e executivos é uma reunião diária, em que uma lista contendo as ações e atividades relevantes à empresa no momento é detalhadamente repassada; sendo relevante, faz parte da lista e é discutido. Essa lista é um artefato válido, e representa um elemento de pressão sobre o grupo gerencial. Mistura elementos quantitativos e qualitativos, a depender do momento e do andamento da reunião. A lista de prioridades é atualmente o instrumento de maior poder dentro da estrutura da organização. Como a reunião é diária, a credibilidade das pessoas em termos a atingir ou não o que foi prometido pode se alterar bruscamente. A evidenciação desses comentários consiste nos diálogos:

Sujeito 1: você usa a informação?

Sujeito 3: todo dia chega o controle de frete, o faturamento, o que está acontecendo ontem, hoje e amanhã. Com essas informações, tomo as decisões principais. Todos os dias, temos uma reunião a partir das 8 h30 da manhã, entram na lista-mestre. 0 que é importante entra na lista mesmo que ocorra um mês depois.

Sujeito 2: com essa reunião, um setor cobra o outro e ele tem a chance de retrucar. É o termômetro da empresa, todo o dia a lista-mestre é atualizada. É uma reunião que demora uma hora e tem todos os dias. Aqui é onde as ações são disparadas e cobradas.

Quando os sócios falam de preferências, dizem que as decisões estratégicas os atraem, mas não sentem confiança na estrutura para delegarem. Gastam muito tempo gerenciando o curto prazo, as questões operacionais e, aí sim, dispõem de controles, que são baseados numa reunião diária onde as coisas relevantes são discutidas. Percebem a necessidade de atuarem no horizonte de longo prazo, mas as circunstâncias não o permitem. Colocaram uma data para isso, mas dependem da evolução de desempenho dos gerentes, que desejam ser diretores.

Sujeito 2: gosto de atuar no estratégico, mas tive que ir para a linha de frente resolver problemas na fábrica e mesmo no cliente. Assim que tiver alguém que possa desenvolver as atividades que são necessárias vou dedicar mais tempo para a estratégia da empresa.

- Pergunta 2. Como as informações da contabilidade gerencial são usadas na empresa?

Durante um período no passado, as informações da contabilidade gerencial eram apresentadas durante uma reunião mensal. Esta tinha uma pauta variada, 
incluindo conteúdos operacionais, como discussão de taxas horárias, transferência de responsabilidades entre departamentos e mesmo cronograma para montagem do orçamento. Dessa forma, o relatório a que os pesquisadores tiveram acesso, artefato gerencial fundamental para a empresa, (i) continha informações históricas basicamente, não prevendo comparações do tipo 'previsto-e-realizado', (ii) apresentava informações financeiras de formas numérica e gráfica; ainda, (iii) apresentava informações financeiras globais, sem detalhes que permitissem questionamentos ou identificação de discussões específicas sobre áreas ou produtos. Essa reunião mensal foi abandonada e, em seu lugar, surgiu uma reunião diária para gerenciar crises do dia a dia. A personalização do sistema de controle é algo vital, integrando o grupo e necessidades técnicas (ROSANAS; VELILLA, 2005).

Dessa maneira, dada a ausência de estrutura organizacional e de pessoas que os apoiem, os sócios são exigidos para resolver os problemas operacionais. Os sócios argumentaram que o relatório ('discurso dos resultados') era mais sofisticado do que o documento disponibilizado ao estudo de caso, inclusive proporcionando informações para análise de investimentos.

Sujeito 1: vocês têm informações gerenciais para discussão dos resultados?

Sujeito 2: não. Hoje não temos informações sobre os resultados financeiros. Nesse momento, na verdade, não temos nem o resultado financeiro referente ao ano passado. [conversa realizada no mês de abril do ano seguinte]

Sujeito 1: vocês não sentem falta dessas informações?

Sujeito 2: sim. Até porque, no passado, nós tínhamos as informações e as discussões mensais.

Sujeito 1: e o que aconteceu?

Sujeito 2: tivemos tantas mudanças, e as prioridades foram mudando. Até que, no final, era melhor atender as prioridades do momento, da crise, do que discutir resultados passados. Com isso paramos de gerar os relatórios e de desenvolver as reuniões. Afinal, mudamos de cidade, mudamos de enfoque e mudamos de empresa, pois a controladora comprou uma empresa nova e fez a incorporação.

Sujeito 1: vocês tinham relatório gerencial antes da mudança?

Sujeito 2: sim. Todos os meses discutíamos os resultados financeiros e mesmo discutíamos os resultados planejados. Surgiram muitos desafios e projetos, e paramos de ver as informações gerenciais mensais.

Sujeito 1: por que vocês pararam de informar os resultados financeiros mensais?

Sujeito 2: no fundo, tantas coisas aconteceram, e os relatórios foram ficando para trás, com menor prioridade. Em algum momento, paramos de gerar os números e de apresentá-los.

Mirvis e Lawer III (1983) indicam que o potencial de impacto das informações contábeis sobre a organização não é algo percebido de maneira indiscutível. Ao contrário, pouco se sabe sobre isso, o que pode afetar o entusiasmo em utilizar tais informações no processo de gestão: "[...] a lack of understanding and knowledge as to what these systems can and cannot do in, to, and for organizations. Also lacking in understanding about how managers and employees use these data" (MIRVIS; LAWLER III, 1983, p. 176).

De qualquer forma, não se pretende considerar que todos os problemas da empresa possam ser decorrentes da ausência das informações, mas sim que ela aumentou problemas existentes e que postergou entendimento e ações. Nesse sentido, Rosanas e Velilla (2005) questionam sobre as limitações do poder contributório do acompanhamento por meio dos relatórios da contabilidade gerencial. 
A responsabilidade pelo desaparecimento dos relatórios gerenciais foi atribuída a um executivo que, uma vez promovido, não teve como se impor e manter as informações. A palavra 'impor' aparece mais de uma vez nas entrevistas, como a limitação e falta de capacidade do colaborador em proporcionar os relatórios desejados em ambiente de mudança. Diálogos que evidenciam os comentários:

Sujeito 3: Precisamos retomar alguns procedimentos que perdemos com a correria. Com a pressão e a correria não esquecemos, mas adiamos o relatório, nem tiramos de lado. Delegamos a uma pessoa que deveria fazer o trabalho que a gente fazia. Delegamos e, ao final do período, perdemos a informação. O cara em quem confiamos não conseguiu gerar a informação, mas perdeu as informações.

Sujeito 3: Os subordinados não mais trabalhavam para ele, mas sim contra ele. Ele começou a abraçar tudo e perdeu procedimento, perdemos informações vitais. No máximo no dia 10 do mês seguinte, apresentávamos todos os resultados do mês anterior, demonstração de resultados por produto, por área. A gente elegia no 80/20: o que aconteceu? Que ações eram tomadas? Imediatas. Era um sistema muito bonito. Ele que montou o sistema e não conseguiu alimentar o sistema.

A crise da ausência de informações gerenciais tem relação com a ausência de sistema integrado que permite o acompanhamento das mudanças. O sistema disponível, não integrado, não permite a obtenção das informações gerenciais com rapidez. Por se tratar de investimento caro (possível sistema ERP), os sócios preferiram investir em aumento de capacidade e postergar o investimento no sistema para momento futuro. Alegam que a migração de sistema de informações é complexo e não poderia ser feito sem relativa estabilidade. Por sua vez, não zelaram para que os dados fossem armazenados, enquanto os esforços foram direcionados para a desativação do sistema antigo sem a compra do novo. Diálogos que evidenciam os comentários:

Sujeito 1: O problema não foi o sistema?

Sujeito 2: Quando você está num mar calmo, você pode travar o timão e deixar o barco seguir.

Sujeito 3: Era muito fácil quando tínhamos o dinheiro em caixa. Pagávamos tudo. A informação era fácil. Quando as coisas se tornaram turbulentas, as coisas mudaram. Quando as coisas se tornaram mais intensas, ele foi perdendo a fonte de informação. O sistema de informação não dava para ele o que precisava. Teve um erro importante. Temos um sistema que se chama [...] era manual mas funcionava muito bem. Por ser um consultor de TI, quem o desenvolveu o fez de maneira muito interessante.

Sujeito 2: Vamos para um ERP e depois de 6-8 meses, o gerente abandonou o que estava fazendo e perdeu informação.

Sujeito 3: Tínhamos contratado o ERP e não tínhamos informações. Como vamos alimentar o ERP? Íamos dar a entrada quando percebemos a situação e paramos tudo. Até então não tinha passado a informação de que tinha perdido tudo. Temos uma promessa de 1 de julho que iremos retomar a reunião e discussão de resultados. Era um trabalho muito bem-feito.

A imagem propagada é de muita participação por parte dos colaboradores, com abertura de informações e discussão:

Sujeito 1: o que posso comentar aqui na empresa?

Sujeito 2: tudo. A empresa é transparente, e tudo deve ser comentado. Até alguns meses atrás, todos os meses, apresentávamos os resultados financeiros para os gerentes.

Em termos de tendência dos negócios, o crescimento é um discurso visto como fundamental na perspectiva dos sócios, comunicado a todos os colaboradores e mesmo ao público externo. Crescimento do negócio é um discurso relevante no modelo de gestão que permite pensar em recompensas futuras ainda não especificadas formalmente. É o ponto inegociável da gestão. Tudo se faz para o 'crescimento' 
(discurso do empreendedorismo), mesmo que não se saiba se ele proporcionará resultado financeiro adequado no curto ou mesmo médio e longo prazos. Diálogo que evidencia o comentário:

Sujeito 8: o faturamento tem crescido muito, e a empresa dobrou o faturamento em curto espaço de tempo.

A diretoria declara que a sua diretriz estratégica consiste em transformar a empresa numa organização de médio a grande porte, enfatizando o crescimento do faturamento. Essa abordagem proporciona sustentação para o discurso do projeto de vida. Uma parte desse discurso pode ser medido sem os relatórios do sistema de informações gerenciais; o faturamento, por exemplo, pode ser acompanhado e reforça o discurso do crescimento. Entretanto, aumento no faturamento não representa aumento no lucro. A literatura discute as questões de imperfeições na mensuração de resultados: "[...] imperfect measurability of the outputs - is well-known, both in theory and in practice, and is a crucial one to our purposes" (ROSANAS; VELILLA, 2005, p. 88).

$O$ poder da persuasão do discurso pode ser reforçado pelo relacionamento entre as pessoas, independentemente dos sistemas formais (ROSANAS; VELILLA, 2005). O discurso do otimismo, do crescimento, tem uma motivação estrutural, fazendo parte das necessidades dos sócios para que os retornos esperados ocorram. Dessa maneira, pensar no crescimento proporciona à empresa a condição de trazer, motivar e reter profissionais relevantes para o seu desenvolvimento. Assim, como Hines (1988) afirma em relação à contabilidade: ao comunicar a realidade, constrói-se também a realidade. Conforme pondera Morgan (1988, p. 482), "objectivity is as much a part of observer as the object observed". Contingencialmente, é a oportunidade para a organização crescer e tornar-se forte. Infelizmente, o discurso não proporciona necessariamente condições de remunerá-los, e esse é um problema relevante. A existência de relatórios gerenciais poderia trazer para a organização o alerta e proporcionar o gerenciamento dos problemas.

A empresa tem um processo produtivo que é um diferencial, pela capacidade de verticalização de um componente produzido. Isso faz com que as empresas queiram ter negócios com ela, dada sua flexibilidade. Também a estrutura de produção proporciona flexibilidade, podendo gerar fidelização dos clientes pela oportunidade de complementação de produção. Não é possível medir e acompanhar esse discurso sem relatórios gerenciais.

A 'vantagem competitiva' (discurso do empreendedorismo) declarada é um discurso que precisa ser constatado na prática. Em outras palavras, algo que é decisivo para a empresa deve trazer, além da receita, lucro. O discurso positivo tem um apoio racional relevante, que permite apoiar as perspectivas 'eficiência e legitimidade' (COVALESKI; DIRSMITH; SAMUEL, 2003). Essa combinação é muito relevante no reforço do discurso do crescimento. Uma vertente apoia e estimula a outra. O diálogo que exemplifica esse discurso:

Sujeito 9: existem alguns fatores na empresa que são únicos no mercado. Ter possibilidade de atender os clientes não apenas fazendo a peça, mas montando em diferentes injetoras é muito relevante no mercado. Além disso, temos espaço físico para novas áreas de produção. Nossos concorrentes mais diretos não apresentam essas propriedades.

Quanto ao desempenho, a indisponibilidade dos relatórios que deveriam conter o 'discurso dos resultados' provocou várias consequências, dentre as quais orientações difusas, confusas e contraditórias, que em nada beneficiam a empresa mas que permitem evitar o pânico que possivelmente ocorreria entre os gestores se fossem divulgados. $\mathrm{Na}$ sequência da entrevista, pode-se perceber a distância entre expectativa e realidade:

Sujeito 1: como estão os negócios?

Sujeito 2: muito bem. Estamos vendendo mais do que no ano passado. Esperamos um crescimento de mais de $20 \%$ das vendas.

Sujeito 1: e o resultado? 
Sujeito 2: melhor também.

Sujeito 1: quanto?

Sujeito 2: não tenho um número exato, mas é melhor. (na realidade, posteriormente, o resultado apurado foi um grande prejuízo, superior ao do ano anterior.)

Sujeito 1: os resultados foram muito ruins. Eu esperava alguma coisa desfavorável, mas o custo é muito superior ao que imaginava; o prejuízo e os empréstimos são maiores do que poderia esperar com o discurso positivo de quem quer crescer muito, comprar outras empresas. O que aconteceu?

Sujeito 4: o resultado não é tão ruim como você viu ontem. Hoje tivemos ajustes e o resultado melhorou um pouco, embora com prejuízo. A causa desses problemas é que, com tantos projetos na empresa, priorizamos o tempo e deixamos de discutir resultados. Com isso, não entendemos várias ocorrências que mudanças na empresa e não ajustamos a contabilidade. Alguns erros poderiam ser detectados, mas não foram. Mudamos pessoas na apuração dos resultados, e vários procedimentos foram mudados sem uma integração. A mudança de regras societárias nos surpreendeu e tratamos várias despesas de maneira inadequada.

Sujeito 4: a realidade é importante. Se não for possível crescer da forma como sonhamos, tudo bem, vamos fazer o que for possível. Vamos ajustar a contabilidade e voltar a fazer a reunião mensal.

Sujeito 1: qual a margem do seu produto?

Sujeito 8: $25 \%$

Sujeito 1: tudo isso! Trata-se de uma margem alta!

Sujeito 4: ele está falando do lucro líquido.

Sujeito 1: então o percentual é mais alto ainda.

Sujeito 8: não é o lucro líquido, e sim resultado bruto.

Sujeito 1: você está falando do preço menos o custo? Se for, está mais alto ainda.

Sujeito 8: não, eu estou falando do lucro bruto.

Sujeito 1: mesmo assim é alto.

- Pergunta 3. Poderia explicar o que poderia tornar as informações da contabilidade gerencial mais úteis?

Aparentemente, irão retomar o relatório de desempenho, numa reunião mensal a ocorrer no início do mês, e isso trará os resultados que tinham antes em termos de planejamento e controle; dado o conjunto de mudanças, a empresa enfrenta vários tipos de dificuldades, como baixo índice de liquidez e endividamento crescente. 0 discurso da necessidade financeira existe, mas não é uma realidade prática para todos atualmente. O discurso de crescimento é para todos, e o discurso do resultado financeiro é para poucos, tais como os sócios, o tesoureiro, relações com o mercado e custos. $O$ passado recente é mencionado com frequência no sentido de que tinham informações e se sentiam satisfeitos com ela, contudo o relatório que os pesquisadores tiveram acesso não mostrava tudo o que era dito na entrevista. O custo real passará a ser apurado no futuro, já que nunca foi totalmente estruturado e apresentado. Quando perguntados sobre perdas, a desativação do sistema de relatório gerencial é também responsabilizado:

Sujeito 3: em cada melhoria, tínhamos a informação de $\mathrm{x}$ reais de volta, pay back.

Tínhamos um programa de kaizen calcado em custos [...]. 
Trabalhávamos com metas, resultados e ações efetivas. Sem resultados, perdemos o meio do caminho. Tomamos ações sem saber o resultado. Sabemos que é positivo, mas não sabemos quanto. Voltaremos a enxergar a partir de julho [o que não ocorreu]. Ele não acompanhou, não se modernizou. Só com procedimentos técnicos. Formatos de interpretação hoje são diferentes pelo IFRS.

Os sócios indicam que informar hoje o que ocorre no caixa pode gerar pânico entre os subordinados; pretendem, assim, proporcionar informações estratificando os subordinados. Entendem que o sistema contábil atual, não integrado, não colabora para informações rápidas, corretas e adequadas aos vários níveis. Implantarão novo sistema, brevemente.

Sujeito 2: Não informamos a situação de caixa, pois isso exige que as pessoas entendam. Se não entenderem o que está acontecendo, podem entrar em pânico e irem embora da empresa. Estamos pensando em preparar uma reunião específica para essa discussão, com os principais gestores da empresa.

A ausência de controles é uma constatação no que se refere à produção e aos estoques. Isso não incomodava os gestores. O estágio de amadurecimento organizacional não valoriza sistemas de informações nem a informação propriamente dita. A perspectiva de Morgan (1988) está presente nesse momento, no sentido de que a subjetividade da construção da realidade não apenas detém a perspectiva técnica; as justificativas para o não-controle, que fogem da ingenuidade e desconhecimento, atingem entendimentos como a lealdade pessoal obtida pelo relacionamento, que impediria ações que pudessem afetar o desempenho da empresa. Existe também um relacionamento com a perspectiva de Hines (1991) que indica que o privilégio de a contabilidade contar com a chamada measurement expertise que impacta o construto da legitimidade para os profissionais. Essa percepção pode existir, também, de fora para dentro (das outras áreas em relação à controladoria, por exemplo). Uma interpretação possível seria que, se a controladoria não se preocupa com controles, é porque não deve se preocupar mesmo. Como a organização não tem uma área de controladoria ou mesmo pessoas desempenhando a função, é constatada a ausência de 'massa crítica' que permitiria contestar ou questionar as ações desenvolvidas, tanto no que se refere a planejamento como a controle.

\section{Estrudo de carso - Discrussão}

Os componentes aglutinadores do discurso organizacional constituído nessa empresa - nos três níveis: 'crença dos sócios', 'empreendedorismo' e 'relatórios contábeis' - são apresentados na Figura (cf. FREZATTI; CARTER; BARROSO, 2014). Como visão geral, os discursos são coerentes entre si e são oferecidos dentro de uma lógica de relacionamento e dependência. Em decorrência da intuição dos sócios (MILLER; FRIESEN, 1984), a confiança pessoal nos colaboradores (MARCH; SIMON, 1958) é o fator que determina a contratação dos mesmos, que ocorre a partir de uma visão macro de que a empresa é uma organização com grande potencial de sucesso dada a vantagem competitiva que possui (COVALESKI; DIRSMITH; SAMUEL, 2003), o que proporciona (já vem ocorrendo tal resultado) e que proporcionará crescimento no mercado. Dessa maneira, o futuro será muito bom para aqueles que estiverem na empresa desde já, aceitando um momento de grandes desafios e esforço pessoal e profissional nos respectivos projetos de vida (ROSANAS; VELILLA, 2005) para terem a recompensa no futuro (3-5 anos). Para que esse estado seja real, o foco nos resultados é o termômetro que permite avaliar quem continua ou sai da empresa, quem cai em desgraça ou é promovido; para tanto, os resultados dos relatórios contábeis se constituem na fonte 'objetiva' que permitiria apurar e explicitar a confirmação dos discursos.

O uso forte da intuição é decorrente do estágio de desenvolvimento da empresa (LESTER; PARNELL; CARRAHER, 2003; MILLER; FRIESEN, 1984) e da lacuna de discurso de informações da contabilidade gerencial num horizonte de tempo. A intuição como parte do processo decisório existiu e existirá, decorrente de experiências, crenças e 
valores e circunstâncias, mas o grau de importância no processo decorre do progresso na estruturação e de sua formalização, e isso depende dos sistemas de informações e da estrutura organizacional da entidade.

O que salta aos olhos no presente caso é que a ausência de informações que confirmem os resultados faz com que resultado signifique várias coisas, exceto os resultados financeiros da empresa. Pode ser pontualidade de entrega, pode ser o faturamento, a não concretização de uma visita a cliente etc. Nessas condições, um conjunto de atividades operacionais e não monetárias pode ser a proxy do resultado financeiro, que não é oferecido. O que permite gerar e aceitar a proxy é a intuição dos sócios (MILLER; FRIESEN, 1984), único guia que a organização tinha durante o período em que as informações não estiveram disponíveis. O fato de trabalharem de maneira conjunta e compartilhada proporciona uma força descomunal na discussão dos problemas, sem uma contrapartida questionadora.

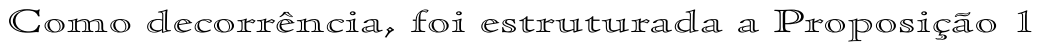

'A intuição dos sócios, baseada em crenças e valores, é o ponto de partida para o início da estruturação do discurso organizacional'.

A confiança pessoal deve ser entendida como ocorrência de acordo com o que foi 'prometido' nas reuniões diárias, que consolidam o poder dos sócios e fragiliza a posição de quem promete. A intuição dos sócios se apoia no que Bourdieu (1990) denominou de habitus, ou seja, algo que foi sendo constituído ao longo da vida das pessoas, gerando e organizando práticas e representações. Algumas condições estão ligadas à existência de habitus, dentre elas algum tipo de estrutura que atue de forma estruturante para organizar as práticas.

Como dlecorrêncial, foil estrutrurracla al Proposição 2

'A confiança pessoal, inicialmente baseada na intuição, é acentuada e fortalecida (ou enfraquece e desaparece) dependendo de confirmações de ocorrências captadas nas informações contábeis.

Conseguir liberar a produção, conseguir novo produto, liberar produto para entrega reforçam a confiança na estrutura produzida pelos habitus. $O$ inverso é verdade também, ou seja, provoca a fragilização e posterior eliminação do colaborador do quadro de empregados da empresa. Dado que o ambiente torna-se continuamente tenso, o que é admitido pelos sócios, o que permite a manutenção da equipe já que o ambiente macroeconômico é propício para a conquista de empregos gerenciais? O conjunto de discursos que gera esse resultado é composto por: (i) promessa de felicidade futura (projeto de vida), atraindo gestores com ambição de crescimento e possibilidade de concretizar o reconhecimento monetário em outro momento e a (ii) necessidade dos sócios congruente com a possibilidade de esperar o futuro grandioso. O discurso dos relatórios gerenciais constitui-se no fiel da balança, reforçando, contestando, reorientando as ações da organização. A ausência desses últimos provoca um vácuo de direcionamento que, nesta organização, ultrapassou dois anos. Por outro lado, resultados negativos podem postergar o benefício do projeto de vida, fragilizando a permanência dos colaboradores que deixam a organização.

O empreendedorismo, parte relevante do discurso organizacional, pode ser entendido por meio dos componentes: (i) vantagem competitiva, (ii) crescimento, (iii) projeto de vida e (iv) foco no resultado. O discurso da vantagem competitiva é fundamental para todo o modelo e pode ser argumentado de maneira forte, com evidências parcialmente capturadas sem os relatórios da contabilidade gerencial. Uma parte da confirmação da vantagem competitiva surge nas conversas com os clientes, discurso externo, quando a estrutura flexível de produção da empresa é elogiada, o que é raro no setor. Essa flexibilidade permite que ela atenda demandas inesperadas, por exemplo, graças à estrutura verticalizada de produção. Além disso, a disponibilidade de espaço físico para expansão de linhas de produção em localidade 
em que a atuação sindical não é radical são variáveis relevantes para a empresa. Aliadas à barreira de entrada imposta pela necessidade de certificação pelos clientes, tornam a empresa muito atraente para novos projetos das empresas automobilísticas. O discurso do empreendedorismo demanda ajustes de percurso percebidos com a disponibilização de relatórios com informações de desempenho. Uma organização que declara estar voltada para 'foco em resultados' precisa de informações para que se perceba que esse discurso está sendo praticado. É a estrutura mencionada por Bourdieu (1990).

O discurso da vantagem competitiva permite a existência de outro discurso que é o do crescimento acelerado. Esse discurso tem como reforço o passado crescente que mostra que, mesmo sem estrutura, a empresa tem crescido acima da média da concorrência. O crescimento coloca a empresa num porte antes não atingido, o que permite melhor posicionamento perante os clientes e ser percebida por eles como 'vencedora'. O discurso otimista é útil para o modelo e precisa ser reforçado por meio dos resultados financeiros de lucro e geração de caixa, o que não tem ocorrido. Significa dizer que a inovação em processos e produtos é uma estratégia relevante para o sucesso da organização e o momento de implementação se apresenta como adequado. A variável mais complexa é o ritmo que essa inovação vai sendo implementada em decorrência da capacidade financeira e crescimento do faturamento. Os resultados financeiros contidos nos relatórios gerenciais são, portanto, vitais para que o conjunto de discursos seja validado e mantido; ainda, as proxies dos resultados financeiros são necessárias mas não suficientes para dar equilíbrio para o conjunto de discursos. Uma consequência do discurso de crescimento é a necessidade de novos investimentos, que consomem recursos financeiros não disponíveis.

Em consequência dos discursos explicitados anteriormente, os sócios precisam de um discurso interno para os gestores; no caso, o projeto de vida, apresentado individualmente. Os executivos são mantidos ou contratados com a perspectiva de que, ao se dedicarem à empresa e assumirem compromisso com as suas metas, no futuro, terão recompensas financeiras como remuneração variável, promoções e status profissional destacado por participarem do sucesso da mesma. Em algum horizonte, a empresa deverá ter ações negociadas em bolsa, o que aumentará a exposição e o prestígio, aumentando o valor de passe de cada executivo vencedor. À semelhança à ideologia cristã, o sofrimento e stress de hoje serão recompensados no futuro, que pode ser 3-5 ou 100 anos.

O fator que torna possível esse modelo e geração de prêmios é denominado de resultado. O resultado financeiro é importante, mas não é conhecido, pois os relatórios gerenciais não mais existem. Na verdade, por não existirem, o discurso resultado deixa de ser obtido por meio da lógica econômica de receita (-) custo (-) despesa (-) impostos = lucro, mas sim pela proxy dos resultados que são visíveis (faturamento, caminhões que foram liberados, saldo de endividamento, problemas resolvidos no cliente). Essa proxy não proporciona uma aproximação adequada ao resultado econômico (margem, lucro e retorno), nem mesmo financeiro (geração de caixa), mas sim indica tendência, sem identificar timing ou quantificar margem. O que é mais relevante é que, ao não dispor de detalhes, ao 'imaginar' que não tem lucro, não sabe onde isso está ocorrendo, dado que não existe procedimento para apurar o custo efetivo (para complementar o padrão). Dessa maneira, a palavra resultado pode significar várias coisas, e o 'discurso' explicativo baseia-se em respostas que possam fazer sentido, sem a 'objetividade' dos números (lucro significa que houve sucesso na relação entre receita menos custo menos despesa menos impostos; prejuízo significa que houve insucesso nessa mesma relação). A sequência de crises operacionais e tensões aumenta o poder dos sócios em termos de pressão e, ao mesmo tempo, a necessidade do gestor de se desdobrar para ter sucesso. E de se esperar que esse modelo traga uma grande tensão e stress nas pessoas, tanto que algumas delas se desligaram da organização. Isso ameaça a continuidade do modelo, dado que identificação e lealdade são elementos dinâmicos que precisam ser alimentados (ROSANAS; VELILLA, 2005). 
Comno decorrêncial, foil estrurturadal al Proposiçäo 3

'Foco em resultados é um discurso que só se sustenta com o acompanhamento e disponibilização de informações, que confirmarão ou não o discurso inicial'.

A volta das informações financeiras através dos relatórios contábeis deve levar os sócios a diminuir o uso da intuição? Se houver um contraponto de alguém na estrutura, isso pode ocorrer. Sem a divulgação dos relatórios gerenciais, é pouco provável que ocorra. Em outras palavras, o modelo demanda uma reflexão sobre a estrutura e o quadro profissional necessários na organização. O que se espera é que o retorno das informações proporcione impacto sobre os gestores. Se os resultados forem favoráveis, provavelmente a coesão da equipe será fortalecida. 0 problema a ser contornado é que não existe espaço para todos no paraíso e alguns dos participantes podem ser desestimulados e podem sair da organização ou deixar de trazer os resultados esperados. Por outro lado, caso os resultados positivos não ocorram, o discurso do projeto de vida passará a ser questionado por todos e deverá ser repensado ou abandonado.

Dessa maneira, a curto prazo, a indisponibilidade e não comunicação dos resultados econômicos é conveniente para o conjunto de discursos alternativos, mas, a médio e longo prazos, não se sustenta e deve provocar desorganização e deterioração do modelo de gestão.

\section{Comsidereaçöes fimais}

Nunca se sabe o que passa pela cabeça das pessoas, menos ainda suas motivações para atitudes. Entretanto, as tensões em uma organização, tanto para aceitar oportunidades de crescimento, como para estruturar o crescimento de maneira a não incorrer em riscos adicionais, mostram-se relevantes. O discurso interno é relevante para dar consistência ao direcionamento das ações e seu acompanhamento. Como o crescimento não necessariamente se mostra cadenciado e organizado, a convivência com as informações gerenciais é a fonte de referência que permite, numa dimensão de curto, médio e longo prazos, proporcionar o reforço para os discursos desejados. Pode também reforçar ou permitir mudanças e troca desses discursos.

Conforme estudado no caso desta empresa de autopeças, o dia a dia da organização, a gestão dos processos administrativos e produtivos, é conduzida com base em um conjunto coeso de construções discursivas que compõem o discurso organizacional. Este conjunto fora anteriormente apresentado, com base nos componentes relacionados às crenças dos sócios, à perspectiva de empreendedorismo e à perspectiva dos relatórios contábeis, mas sem a caracterização do processo de constituição desse aglomerado discursivo e da própria organização.

Conforme descrito na seção de discussão do presente estudo de caso, o discurso organizacional que suporta a dinâmica gerencial e contribui à própria constituição da empresa tem na intuição dos sócios um ponto de partida considerável (cf. Proposição 1); mais do que ponto de partida, as crenças e os valores organizacionais dos sócios representam um ponto de referência fundamental ao dia-a-dia da empresa, pois diversas questões gerenciais são recorrentemente referenciadas neles.

Não obstante, informações gerenciais sobre o desempenho dos negócios - não exatamente relatórios e demonstrações comumente referenciados na literatura de contabilidade gerencial, mas as proxies utilizadas nas reuniões diárias de acompanhamento operacional, baseadas retoricamente em contabilidade - são utilizadas para sustentação da gestão referenciada na intuição dos sócios (cf. Proposições 2 e 3). Ou melhor, o discurso organizacional nesta empresa é alimentado com argumentos típicos de contabilidade gerencial, contribuindo assim à sustentação do modelo gerencial e da própria organização, ainda que determinados artefatos relevantes de contabilidade gerencial tenham sido abandonados durante algum tempo. 
O sistema de informações gerenciais proporciona monitoramento e indicações de necessidades de ações que podem reforçar, mudar ou mesmo criar novos discursos. Esse poder nem sempre é percebido nas organizações. Como achado relevante do estudo de caso desenvolvido, deve ser mencionado que a percepção de que as informações são necessárias para o processo de tomada de decisão considera que isso seja verdadeiro para todos os níveis e para todas as decisões da organização, principalmente para o nível gerencial. Na verdade, a necessidade das pessoas em situações em que informações não estejam disponíveis pode demandar mais à intuição do que a 'objetividade' das informações contábeis. A consequência dessa ausência é que as pessoas acabam desenvolvendo formas de atuação e sem que deixem de sentir falta das informações contábeis. Em termos de discursos, o silêncio não deixa de ser algo a ser dito. O risco para a organização consiste em deixar de perceber esse descolamento e só perceber a existência de problemas quando esses se tornarem muito relevantes e evidentes, talvez tarde demais.

Considerando a questão de pesquisa proposta inicialmente, concluímos que a contabilidade gerencial tem impacto considerável sobre os discursos organizacionais desenvolvidos internamente; esses discursos contribuem à constituição e manutenção da organização e têm na contabilidade gerencial - ou mesmo em proxies estabelecidas sobre resíduos de contabilidade gerencial - suporte informacional relevante para a própria manutenção e o próprio fortalecimento.

Quanto a estudos futuros percebemos várias pesquisas possíveis para trazer conhecimentos relevantes para o tema. Um deles diz respeito a como os discursos foram criados, suas demandas, suas tensões e seus aspectos contextuais. Afinal, ao longo de sua criação e utilização, que tipo de lógicas foram consideradas influenciando, reforçando ou restringindo os discursos. Outra oportunidade de pesquisa se refere à retomada do uso das informações contábeis e sua credibilidade interna. Finalmente, outra oportunidade, algo não possível no presente caso, diz respeito à visão dos perdedores, aqueles que saíram da organização e não foram ouvidos para contar suas histórias.

Referêuncias

BARROSO, M. F. G. The discursive constitution of the 'management control' organisation. 2014. 149 f. Tese (Doutorado em Contabilidade) - Faculdade de Economia, Administração e Contabilidade, Universidade de São Paulo, São Paulo, 2014.

BERGER, P. L.; LUCKMANN, T. The social construction of reality. Wrights Lane: Penguin, 1966.

BOURDIEU, P. The logic of practice. Stanford: Stanford University Press, 1990.

BURRELL, G.; MORGAN, G. Sociological paradigms and organisational analysis. Vermont: Ashgate, 1979.

CHAMBERS, R. J. Accounting, evaluation and economic behavior. Houston: Scholars Book, 1974.

CHIA, R. Discourse analysis as organizational analysis. Organization, v. 7, n. 3, p. 513-518, 2000.

COUGHLAN, P.; COGHLAN, D. Action research for operations management. International Journal of Operations \& Production Management, v. 22, n. 2, p. 220-240, 2002.

COVALESKI, M. A.; DIRSMITH, M. W.; SAMUEL, S. Changes in the institutional environment and the institutions of governance: extending the contributions of transaction cost economics within the management control literature. Accounting, Organizations and Society, v. 28, n. 5, p. 417-441, 2003. 
FREZATTI, F.; CARTER, D. B.; BARROSO, M. F. G. Accounting without accounting: Informational proxies and the construction of organisational discourses. Accounting, Auditing \& Accountability Journal, v. 27, n. 3, p. 426-464, 2014.

HENDRIKSEN, E. S.; BREDA, M. F. Van. Teoria da contabilidade. São Paulo: Atlas, 1999.

HINES, R. D. Financial accounting: in: communicating reality, we construct reality. Accounting, Organizations and Society, v. 13, n. 3, p. 251-261, 1988.

HINES, R. D. The FASB's conceptual framework, financial accounting and the maintenance of the social world. Accounting, Organizations and Society, v. 16, n. 4, p. 313-331, 1991.

HOWARTH, D. R.; STAVRAKAKIS, Y. Introducing discourse theory and political analysis. In: HOWARTH, D. R.; NORVAL, A. J.; STAVRAKAKIS, Y. (Ed.). Discourse theory and political analysis. Manchester: Manchester University Press, 2000. p. 1-23.

KNIGHTS, D.; COLLINSON, D. Disciplining the shopfloor: a comparison of the disciplinary effects of managerial psychology and financial accounting. Accounting, Organizations and Society, v. 12, n. 5, p. 457-477, 1987.

LACLAU, E. Emancipation(s). London: Verso, 1996.

LACLAU, E.; MOUFFE, C. Hegemony and socialist strategy: towards a radical democratic politics. 2. ed. London: Verso, 2001.

LAVOIE, D. The accounting of interpretations and the interpretation of accounts: the communicative function of "the language of business". Accounting, Organizations and Society, v. 12, n. 6, p. 579-604, 1987.

LESTER, D. L.; PARNELL, J. A.; CARRAHER, S. Organizational life cycle: a five-stage empirical scale. International Journal of Organizational Analysis, v. 11, n. 4, p. 339-354, 2003.

LLEWELLYN, S.; MILNE, M. J. Accounting as codified discourse. Accounting, Auditing \& Accountability Journal, v. 20, n. 6, p. 805-824, 2007.

MACINTOSH, N. B. Accounting, accountants and accountability: poststructuralist Positions. London: Routledge, 2002.

MACINTOSH, N. B. et al. Accounting as simulacrum and hyperreality:

perspectives on income and capital. Accounting, Organizations and Society, v. 25, n. 1 , p. $13-50,2000$.

MARCH, J.; SIMON, H. Organizations. New York: Wiley, 1958.

MATTHEWS, P. H. The concise Oxford dictionary of linguistics. 2. ed. Oxford: Oxford University Press, 2007.

MILLER, D.; FRIESEN, P. H. A longitudinal study of the corporate life cycle. Management Science, v. 30, n. 10, p. 1161-1183, 1984.

MIRVIS, P. H.; LAWLER III, E. E. Systems are not solutions: Issues in creating information systems that account for the human organization. Accounting, Organizations and Society, v. 8, n. 2-3, p. 175-190, 1983.

MORGAN, G. Accounting as reality construction: towards a new epistemology for accounting practice. Accounting, Organizations and Society, v. 13, n. 5, p. 477-485, 1988.

ROSANAS, J. M.; VELILLA, M. The ethics of management control systems: developing technical and moral values. Journal of Business Ethics, v. 57, n. 1, p. 83-96, 2005.

STAKE, R. The art of case research. Newbury Park, CA: Sage, 1995. 
WEICK, K. E. Sensemaking in organizations. Thousand Oaks, CA: Sage, 1995.

WILLMOTT, $\mathrm{H}$. Theorizing contemporary control: some post-structuralist responses to some critical realist questions. Organization, v. 12, n. 5, p. 747-780, 2005.

Submissão: 17/05/2013

Aprovação: 23/04/2015 
